\title{
A genotype-phenotype correlation for GJB2 (connexin 26) deafness
}

\section{K Cryns*, E Orzan*, A Murgia*, P L M Huygen, F Moreno, I del Castillo, G Parker Chamberlin, H Azaiez, S Prasad, R A Cucci, E Leonardi, R L Snoeckx, P J Govaerts, P H Van de Heyning, C M Van de Heyning, R J H Smith, G Van Camp}

J Med Genet 2004;41:147-154. doi: 10.1136/jmg.2003.013896

\section{* All authors contributed equally}

See end of article for authors' affiliations

Correspondence to:

Guy Van Camp,

Department of Medical

Genetics, University of Antwerp-UIA,

Universiteitsplein 1, B-

2610 Antwerp, Belgium;

guy.vancamp@ua.ac.be

Revised version received 31 October 2003

Accepted

3 November 2003

\begin{abstract}
Introduction: Mutations in GJB2 are the most common cause of non-syndromic autosomal recessive hearing impairment, ranging from mild to profound. Mutation analysis of this gene is widely available as a genetic diagnostic test.

Objective: To assess a possible genotype-phenotype correlation for GJB2.

Design: Retrospective analysis of audiometric data from people with hearing impairment, segregating two GJB2 mutations.

Subjects: Two hundred and seventy seven unrelated patients with hearing impairment who were seen at the ENT departments of local and university hospitals from Italy, Belgium, Spain, and the United States, and who harboured bi-allelic GJB2 mutations.

Results: We found that 35delG homozygotes have significantly more hearing impairment, compared with 35delG/non-35delG compound heterozygotes. People with two non-35delG mutations have even less hearing impairment. We observed a similar gradient of hearing impairment when we categorised mutations as inactivating (that is, stop mutations or frame shifts) or non-inactivating (that is, missense mutations). We demonstrated that certain mutation combinations (including the combination of 35delG with the missense mutations L90P, V37I, or the splice-site mutation IVS1+1G $>$ A, and the V37I/V37I genotype) are associated with significantly less hearing impairment compared with $35 \mathrm{del}$ G homozygous genotypes.

Conclusions: This study is the first large systematic analysis indicating that the GJB2 genotype has a major impact on the degree of hearing impairment, and identifying mild genotypes. Furthermore, this study shows that it will be possible to refine this correlation and extend it to additional genotypes. These data will be useful in evaluating habilitation options for people with GJB2 related deafness.
\end{abstract}

A pproximately one child in 500-650 is born deaf, making hearing impairment the most frequent sensory defect. ${ }^{12}$ In more than half of these children, the cause is monogenic ${ }^{3}$ with the inheritance pattern being autosomal dominant $(20 \%)$, autosomal recessive $(80 \%)$, X-linked $(1 \%)$ or mitochondrial $(<1 \%)$. In about $70-80 \%$ of cases other stigmata are absent and the hearing impairment is classified as non-syndromic. To date, over 70 non-syndromic loci have been mapped and 35 deafness genes have been identified. ${ }^{4}$ Despite this heterogeneity, up to $50 \%$ of prelingual recessive non-syndromic deafness can be attributed to mutations in GJB2 (MIM 121011)..$^{5-9}$ A few specific mutations in this gene also underlie autosomal dominant non-syndromic deafness DFNA3 (MIM 601544), but its prevalence is very low..$^{11}$ Although a broad spectrum of recessive deafness mutations in the GJB2 gene is known, ${ }^{12}{ }^{13}$ one particular mutation, the 35delG mutation, is very frequent in populations of European origin. ${ }^{14}$ This single base pair deletion results in a frameshift and a premature protein truncation. The frequency of 35delG is highest in countries close to the Mediterranean, where the carrier frequency is between $1 / 30$ and $1 / 35 .^{14}$ In these countries, 35delG accounts for $70 \%$ of all GJB2 alleles. Although once thought to represent a mutational hotspot within GJB2, background genotyping has shown that 35delG derives from a founder ancestor. ${ }^{16}$

The protein encoded by GJB2 is gap junction connexin 26 (CX26). Six connexin monomers assemble to form a hexameric connexon, which localises to the cell membrane. Oligomerisation with a connexon from an adjacent cell results in channel formation, facilitating intercellular transport of small metabolites and ions. In the cochlea, CX26 is expressed in the supporting cells and fibrocytes of the cochlear duct, where it may be involved in the recycling of potassium ions from hair cells back to the endolymph. Disruption of CX26 gap junctions presumably impairs recycling of potassium ions thereby causing hearing impairment.

Although GJB2 plays an important role in non-syndromic childhood deafness, only a few studies describe the clinical characteristics of GJB2 associated hearing loss in detail. According to these reports, hearing impairment in prelingually deaf children with bi-allelic GJB2 mutations affects all frequencies, varies from mild to profound even within the same family, and is most commonly non-progressive. ${ }^{17-20}$ In the present study, we analysed audiometric characteristics associated with various types of GJB2 mutations to delineate possible genotype-phenotype correlations.

\section{METHODS}

\section{Clinical evaluation}

Clinical data were derived from patients from Belgium, Italy, Spain, and the United States, who tested positively for biallelic GJB2 mutations in routine diagnostic testing. People with hearing impairment underwent otoscopic examinations and pure tone audiometry with a diagnostic audiometer in a

Abbreviations: ASPCR, allele-specific polymerase chain reaction; $\mathrm{HL}$, hearing loss; ISO, International Standards Organization; PTA, pure tone average; SSCP, single strand conformational polymorphism 
soundproof room following International Standards Organization (ISO) standards. ${ }^{21}$ People with features of syndromic hearing impairment were excluded from the study. Individual binaural mean pure tone thresholds ( $\mathrm{dB}$ hearing loss (HL), air conduction level) were available for $0.5,1,2$, and $4 \mathrm{kHz}$. Out of scale measurements were coded as $120 \mathrm{~dB}$ hearing loss. Median threshold values were calculated for each relevant subgroup of patients. The severity of hearing impairment was defined by the degree of hearing loss in the better ear: average thresholds between 21-40 dB were considered as mild hearing impairment, $41-70 \mathrm{~dB}$ as moderate hearing impairment, 71-95 $\mathrm{dB}$ as severe hearing impairment, and $>95 \mathrm{~dB}$ as profound deafness. ${ }^{22}$

In Italian children aged between 6 months and 2 years, individual binaural tone threshold was obtained by visual reinforcement audiometry, and confirmed with click evoked auditory brainstem response (ABR) also called brainstem evoked response audiometry.

American and Belgian children below the age of 2 were tested by conditioned oriented reflex audiometry, auditory brainstem response, or pure tone audiometry. There were no Spanish children below the age of 2 in our study sample.

\section{GJB2 mutation analysis}

Various methods were used for mutation analysis of the GJB2 gene. For the Italian samples, GJB2 mutation screening was performed by single strand conformational polymorphism (SSCP) under various conditions followed by DNA sequencing. ${ }^{17}$ The Belgian samples were prescreened for 35delG. No further testing was done on people identified as 35delG homozygotes. If only one mutant allele was detected, the entire coding region of GJB2 was sequenced. Samples from Spanish patients were screened first for the 35delG mutation. In heterozygotes, heteroduplex analysis of the open reading frame, splice sites and promoter of GJB2 was completed, followed by sequencing of any DNA fragments showing abnormal gel-migration patterns. If heteroduplex analysis was normal, the entire open reading frame, splice sites and promoter of GJB2 were sequenced.

For the samples from American patients, the initial screen was an allele-specific polymerase chain reaction (ASPCR) assay to detect the presence of the $35 \mathrm{delG}$ allele variant using previously described primers. ${ }^{23}$ In people heterozygous for the 35delG allele, the coding sequence of GJB2 (exon 2) was screened for other allele variants by SSCP using MDE gels (FMC BioProducts, Rockland, ME). All abnormal band shifts were sequenced; if no abnormal band shifts were identified, the non-coding exon of GJB2 (exon 1) was sequenced. In cases in which the initial ASPCR screen failed to demonstrate a 35delG allele, exon 2 was screened by SSCP, again using MDE gel electrophoresis; samples were sequenced if shifts were observed. If a single coding mutation was detected, the non-coding exon of GJB2 (exon 1) was sequenced. ${ }^{24}$

Mutations that were listed as non-syndromic deafness mutations on the Connexin deafness homepage ${ }^{13}$ were all considered to be pathogenic. For sequence variants that were not described previously or for variants with an uncertain pathogenic state, the evolutionary conservation between Homo sapiens, Mus musculus, Cavia porcellus, and Ovis aries was calculated using the ConSeq web server. ${ }^{25}$

In families with more than one affected sibling, we considered genotypic and audiometric data from only one randomly chosen deaf individual per family. All people segregating the M34T mutation were excluded because the pathogenic nature of this mutation is not clear. ${ }^{26}$

\section{Statistical analysis}

To analyse whether the degree of hearing impairment was randomly distributed across the various $35 \mathrm{delG} /$ non-35delG and inactivating/non-inactivating genotypes (35delG/35delG, 35delG/non-35delG, non-35delG/non-35delG; inactivating/ inactivating, inactivating/non-inactivating, non-inactivating/ non-inactivating), $\chi^{2}$ testing was performed using the hearing impairment classification of mild, moderate, severe, and profound. Missense mutations and $3 \mathrm{bp}$ deletions resulting in a deletion of an amino acid were considered as non-inactivating; splice site mutations, insertions, nonsense mutations, duplications and deletions of more than $3 \mathrm{bp}$ were considered as inactivating mutations. Subsequently, the $3 \times 4$ contingency tables were reduced to the appropriate $2 \times 2$ contingency table and Fisher's exact probability testing was performed to analyse whether certain classes of hearing impairment occurred more often in a specific genotype category than would be expected by chance alone.

Comparisons by hearing impairment classification between several specific mutation combinations (with $\mathrm{n}>2$ observations) were made using the $\chi^{2}$ test. Pairwise comparisons between subgroups were performed using Fisher's exact probability test. Therefore, the pure tone average of thresholds at $0.5,1,2$, and $4 \mathrm{kHz}\left(\mathrm{PTA}_{0.5-4 \mathrm{kHz}}\right)$ was dichotomised around the highest value observed in the $35 \mathrm{delG} /$ non-35delG or non-35delG/non-35delG genotype class. The level of significance used was $\mathrm{p}=0.05$.

\section{RESULTS}

\section{GJB2 mutation spectrum}

This study was conducted on 277 unrelated patients with prelingual hearing impairment with bi-allelic GJB2 mutations, who were seen at the ear, nose, and throat departments of local and university hospitals (30 Belgian, 131 Italian, 42 Spanish, and 74 American patients). The mutations in these patients comprise seven different homozygous genotypes and 50 different compound heterozygous genotypes. The changes include missense mutations, small deletions and insertions, nonsense mutations, one duplication, and one splice site mutation. Of the homozygous genotypes, five are expected to lead to an absent or truncated protein (anticipated null allele or inactivating mutation). In 16 out of 50 compound heterozygous genotypes, both changes are null alleles. The inactivating/non-inactivating and non-inactivating/non-inactivating mutation combinations represent 29 and 5 out of 50 compound heterozygous genotypes, respectively. When considering the total study sample, $78 \%$ of the patients (216/277) inherited two inactivating mutations, 19\% (53/277) inherited an inactivating and a non-inactivating mutation, and 3\% (8/ 277) inherited two non-inactivating mutations.

Sixty percent of our total sample were homozygous for $35 \mathrm{delG}$, with this mutation accounting for $75.5 \%$ (418/554) of all mutant alleles. Homozygosity for 35delG was least frequent in the American sample (34/74, 46\%) and most frequent in the Belgian sample $(22 / 30,73 \%)$. In the Spanish and Italian samples, $55 \%(23 / 42)$ and $66 \%$ (87/131) of patients, respectively, were 35 delG homozygotes. The high percentage in the Belgian sample may reflect a selection bias since people were first screened for $35 \mathrm{del} G$ and mutation analysis of the complete coding region was performed only if a single 35delG allele was detected.

\section{Audiometric analysis of patients with bi-allelic GJB2 mutations}

Genotype and hearing impairment distribution in biallelic GJB2 patients

Fig 1 shows the distribution of the classes of hearing impairment in the various $35 \mathrm{delG} /$ non-35delG and inactivating/non-inactivating genotype categories. In the 35delG/35delG genotype category, 63\% (105/166) showed profound hearing impairment and 29\% (47/166) were severely affected. Mild and moderate hearing impairment 

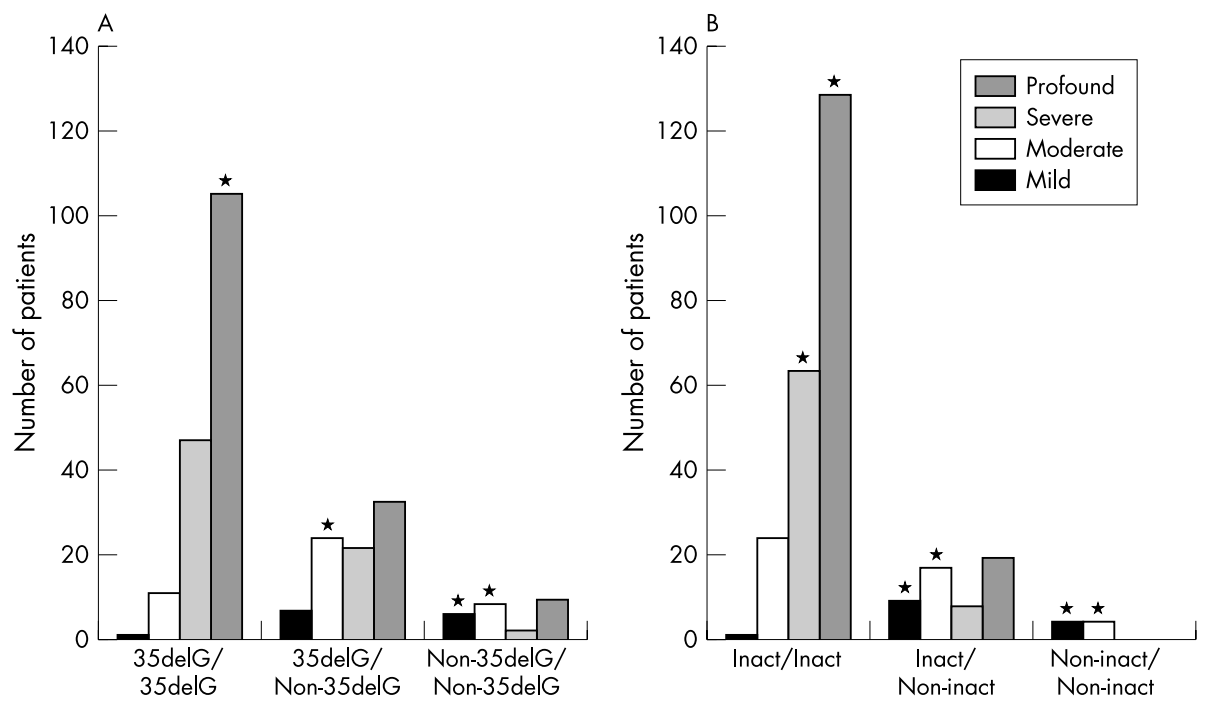

Figure 1 Distribution of the four classes of hearing impairment over the possible 35delG/non-35delG (A) and inactivating/non-inactivating (B) genotypes. The number of patients is indicated on the $y$ axis. $\chi^{2}$ testing indicated that a non-random association exists between the degree of hearing impairment and the mutation combination. For the inactivating/non-inactivating genotypes, a reduced contingency table was constructed, combining the mild and moderate category. Asterisks indicate significantly high relative frequency according to the Fisher's exact probability test.

was observed in $<1 \%(1 / 166)$ and $8 \%(13 / 166)$ of $35 \mathrm{delG}$ homozygous people, respectively. $\chi^{2}$ testing indicated that the different classes of hearing impairment were not randomly distributed across the different genotype categories $\left(\chi^{2}, 55.75\right.$ (df 6) and 66.19 (df 4) for the 35delG/non-35delG and inactivating/non-inactivating categories, respectively). To evaluate whether certain classes of hearing impairment occurred more frequently in combination with a certain genotype than would be expected on the basis of chance alone, Fisher's exact probability testing was performed. The 35delG/35delG genotype was significantly associated with profound hearing impairment and the inactivating/inactivating genotype category was significantly associated with profound and severe hearing impairment. In addition, the 35delG/non-35delG and non-35delG/non-35delG genotypes showed significant associations with mild or moderate hearing impairment and so did the inactivating/non-inactivating and non-inactivating/non-inactivating mutation combinations.

\section{Comparison of threshold values between specific GJB2 genotypes}

To determine whether sample differences existed between people with a similar mutation combination, $\mathrm{PTA}_{0.5-4 \mathrm{kHz}}$ values for 35 delG homozygotes and for people with an inactivating/inactivating genotype were compared between countries. We found no significant difference between people from different countries in either the $35 \mathrm{delG} / 35 \mathrm{delG}$ group $\left(\chi^{2}\right.$ test) or the inactivating/inactivating mutation combination group ( $\chi^{2}$ test, data not shown). The threshold measurements of all 35delG homozygotes were therefore combined into one group to compare thresholds of people with different specific mutation combinations. The P5 (lower $5^{\text {th }}$ centile of the 35 delG/35delG patients) and P10 (lower $10^{\text {th }}$ centile of the $35 \mathrm{delG} / 35 \mathrm{delG}$ patients) PTA levels for the combined group were at $\sim 60$ and $70 \mathrm{~dB}$ HL respectively (data not shown). As illustrated by fig 2, patients with 35delG/ delE120, 35delG/IVS1+1G>A, 35delG/L90P, 35delG/V37I, or V37I/V37I genotypes clearly showed significantly less severe hearing impairment with respect to $35 \mathrm{del}$ homozygotes (Fisher's exact test). Remarkably, it was possible to show that some genotypes that occurred only once were also associated with significantly less severe hearing impairment compared to 35delG homozygotes (313del14/313del14,
W24X/313dell4, L90P/V95M， R184P/IVS1+1G>A， L90P/ V153I, V63M/D159N, Y65X/L90V, V37I/R143W; fig 2). No significant differences were found between 35delG homozygotes and people with a 35delG/Rl43W, 35delG/E147K, 35delG/313dell4, 35delG/W24X, 35delG/V95M, 35delG/ W77R, 35delG/E47X, 35delG/167delT, or 35delG/R184P mutation combination (fig 3). Although the genotypes 35delG/167delT and 35delG/R184P showed no significant difference with 35delG homozygotes when dichotomised around the highest value (fig 3), they did show a significant excess of cases with relatively mild hearing impairment when dichotomised around another value (respectively $\mathrm{p}=0.006$ and $\mathrm{p}=0.014$ when dichotomising around $51.25 \mathrm{~dB}$ for $35 \mathrm{delG} / 167 \mathrm{delT}$ and $70 \mathrm{~dB}$ for $35 \mathrm{delG} / \mathrm{R} 184 \mathrm{P})$. This is probably the consequence of the relatively wide variation in the degree of hearing impairment for these two genotypes. There was no substantial difference in thresholds between people with the same mutation combination coming from different countries (data not shown).

Comparison of threshold values between the various $35 \mathrm{delG} /$ non-35delG and inactivating/noninactivating genotypes with exclusion of genotypes that cause significantly less severe hearing impairment

Because some specific genotypes were associated with significantly less severe hearing impairment with respect to 35delG homozygotes, the statistically significant differences we noted in fig 1 could reflect the presence of less severe mutation combinations within specific subgroups. To assess this possibility, we repeated the analyses pertaining to fig 1 , after excluding all the genotypes that had been found to be significantly less severe in comparison to $35 \mathrm{delG} / 35 \mathrm{delG}$ (fig 2). After exclusion, it appeared that hearing impairment overall was still not randomly distributed across the various categories of $35 \mathrm{delG} /$ non35delG $\left.\left(\begin{array}{llll}\chi^{2} & 6.98 & (\mathrm{df} & 2\end{array}\right)\right)$ and inactivating/non-inactivating ( $\chi^{2} 19.61$ ( $\left.\mathrm{df} 2\right)$ ) genotypes. Despite this finding, Fisher's exact probability testing indicated that each of the different 35delG/non-35delG genotypes separately did not occur more frequently in combination with certain classes of hearing impairment. Inactivating/noninactivating and non-inactivating/non-inactivating genotypes, however, were still significantly associated with 


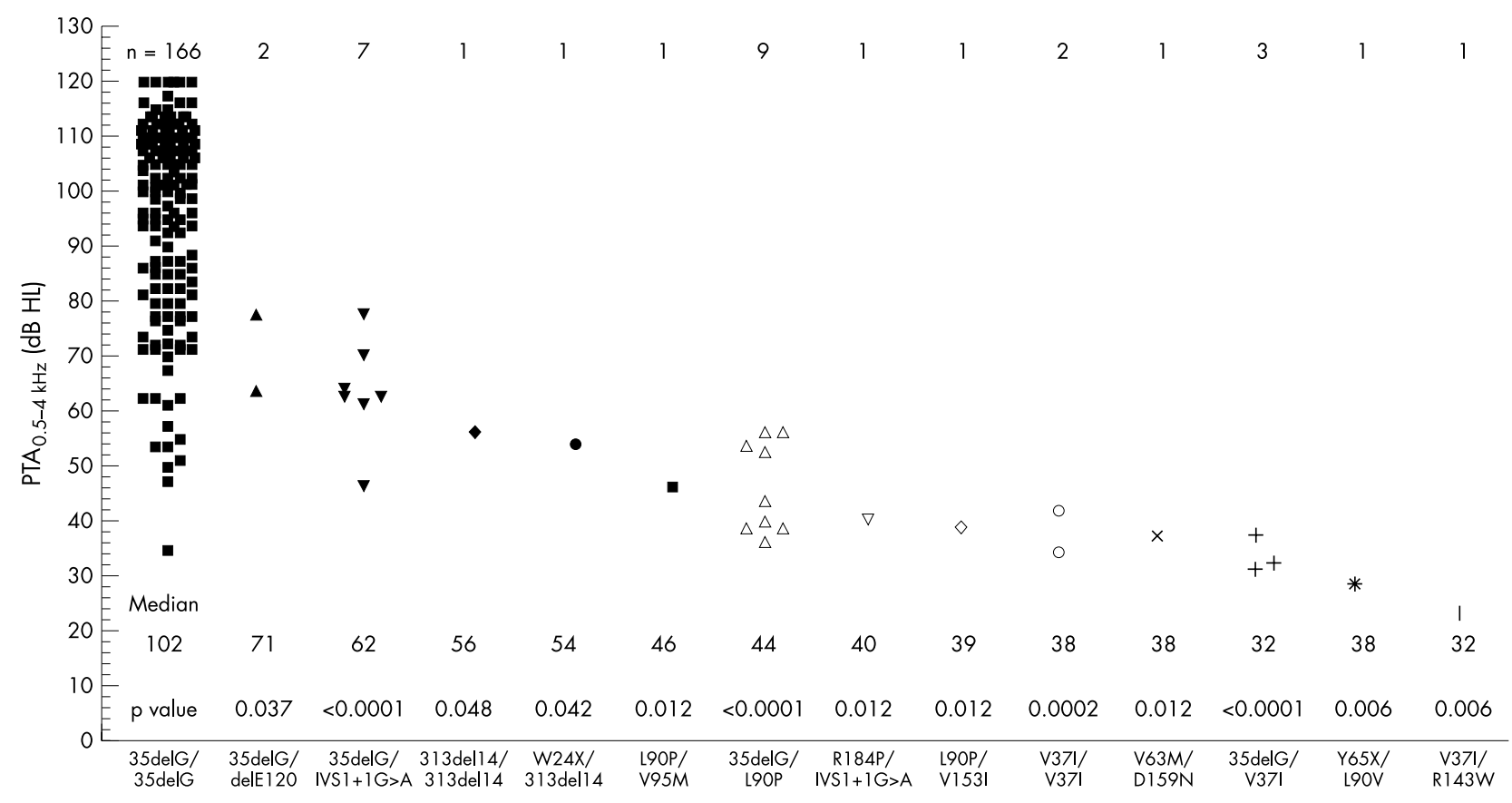

Figure 2 Binaural PTA $0.5-4 \mathrm{kHz}$ (dB HL) for 35delG homozygous patients compared with subgroups of patients with specific testable GJB2 genotypes that showed significantly less severe hearing impairment in comparison to 35 delG homozygotes in Fisher's exact probability testing. The number of observations ( $\mathrm{n})$, the median value $(\mathrm{dB} \mathrm{HL})$ and the $\mathrm{p}$ value are indicated for each subgroup.

moderate hearing impairment, while all other significant associations indicated in fig lB disappeared (fig 4).

Analysis of progression in bi-allelic GJB2 patients The threshold distribution in each nationality was similar (data not shown), as were age distributions across countries (median ages, 4-7 years; range, 0-67 years). We performed linear regression analysis of thresholds on age and found no significant age effect on threshold with only one exceptionthe Italian patients showed slight but significantly less severe hearing impairment with increasing age (data not shown). Because it can be difficult to reliably assess pure tone thresholds in very young children, we repeated regression analysis of the Italian sample after excluding patients aged $<2$ years and found the threshold-age effect no longer significant.

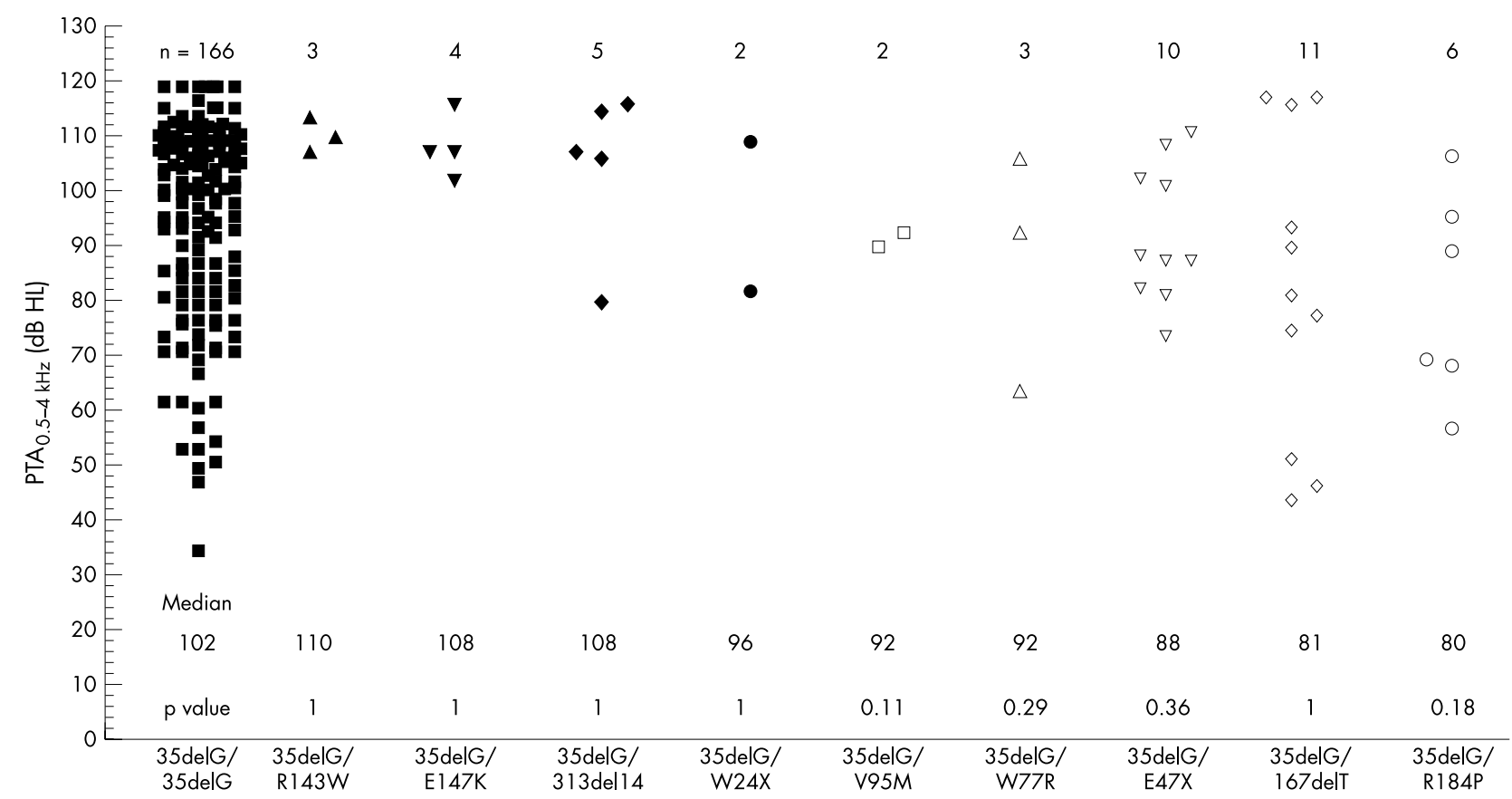

Figure 3 This shows the same as fig 2, but now including the subgroup of patients with specific testable GJB2 genotypes who did not show significantly less severe hearing impairment in comparison to 35delG homozygotes in Fisher's exact probability testing. The number of observations $(\mathrm{n})$, the median value $(\mathrm{dB} \mathrm{HL})$ and the $\mathrm{p}$ value are indicated for each subgroup. The PTA $\mathrm{A}_{0.5-4 \mathrm{kHz}}$ values were dichotomised as described. Note that $35 \mathrm{delG} / 167 \mathrm{delT}$ and 35delG/R184P show an excess of patients with remarkably mild degrees of hearing impairment. 


\section{DISCUSSION}

Mutations in GJB2 account for up to $50 \%$ of prelingual recessive non-syndromic deafness in the white population. Screening of this gene is relatively easy, thereby allowing molecular diagnosis for non-syndromic deafness. In the present study, we investigated the audiological characteristics in a large number of GJB2 hearing-impaired people originating from Belgium, Italy, Spain, and the United States, to delineate potential genotype-phenotype correlations. Several interesting features emerged. Although hearing loss in people with two GJB2 allele variants ranged from mild to profound, the non-random distribution pattern of different categories of hearing impairment over the various $35 \mathrm{delG} /$ non-35delG (fig lA) and inactivating/non-inactivating genotypes (fig 1B) suggested a correlation between the type of mutation and the severity of hearing impairment. Statistical analysis indeed confirmed that certain classes of hearing impairment occurred significantly more often in association with certain genotypes than would be expected by chance alone. As no significant difference existed in the degree of hearing impairment between people with similar mutation combinations originating from different countries, hearing thresholds in people with similar GJB2 genotypes were combined to analyse the effect of specific mutation combinations. Interestingly, 35delG homozygotes showed significantly more hearing impairment with respect to 35delG/delE120, 35delG/ IVSI+lG $>$ A, 35delG/L90P, 35delG/V37I, and V37I/V37I genotypes (fig 2). A significant difference was also seen with a number of mutation combinations that occurred only in a single patient (313del14/313del14, W24X/313del14, L90P/ V95M， R184P/IVS1+1G>A， L90P/V153I，V63M/D159N, Y65X/L90V, V37I/R143W; fig 2). However, as the latter findings are based on a single patient, they should be interpreted cautiously and should be corroborated by additional data. The genotypes involving V37I and V153I raise questions. The V37I variant has been reported as a mutation and as a polymorphism, ${ }^{57-29}$ and it seems to be relatively frequent in the Asian population. It was noted that the prevalence in the Asian hearing loss population is lower than expected based on the carrier-frequency. ${ }^{30}$ Therefore, Bason et $\mathrm{al}^{30}$ suggested that this discrepancy is caused by a distortion of the V37I frequency in the control population, a selection bias towards individuals with more severe hearing impairment, decreased penetrance, or the fact that V37I is a polymorphism but not a mutation. Also the pathogenic state of V153I is uncertain. It is listed as a rare polymorphism, ${ }^{13}$ and valine at position 153 shows an average conservation between Homo sapiens, Mus musculus, Cavia porcellus, and Ovis aries. However, Kenna et $\mathrm{al}^{31}$ reported that this variant may represent a mild recessive mutation and we detected it only once in 1348 Italian individuals who were screened for GJB2. If V37I and V153I are polymorphisms, it is not surprising that the hearing impairment of patients with a 35delG/V37I, V37I/V37I and L90P/V153I genotype was significantly less than that of $35 \mathrm{delG}$ homozygous patients. However, as we demonstrate in the present study that the phenotypic variability of GJB2 patients can largely be attributed to their genotype, it is possible that V37I and V153I are pathogenic variants leading to a mild phenotype.

A compilation of audiological data from previous studies confirms to some extent that specific relevant GJB2 genotypes are associated with relatively mild hearing impairment (for references see table 1 ). Like the present study, Janecke et $\mathrm{al}^{34}$ found that the distribution of homozygotes for truncating GJB2 mutations and other genotypes among the categories of hearing impairment differed significantly. In addition, they reported that the distribution of genotypes with and without L90P differed significantly. They concluded that the L90P mutation in trans with any other recessive mutation is predominately associated with mild or moderate hearing impairment, thereby corroborating our results. Although their findings were variable, they suggested that hearing impairment in people cosegregating the $35 \mathrm{delG} / \mathrm{L} 90 \mathrm{P}$ genotype is progressive and may even be associated with episodes of sudden sensorineural hearing loss. Regression analysis on our 9 35delG/L90P compound heterozygotes (aged 1-35) failed to find significant progression (data not shown), not supporting the findings of Janecke et al, and none of these people reported episodes of sudden sensorineural hearing loss. Also Denoyelle et $\mathrm{al}^{19}$ reported that the distributions of compound heterozygotes and 35delG homozygotes among the hearing-loss subgroups differed significantly, which is in
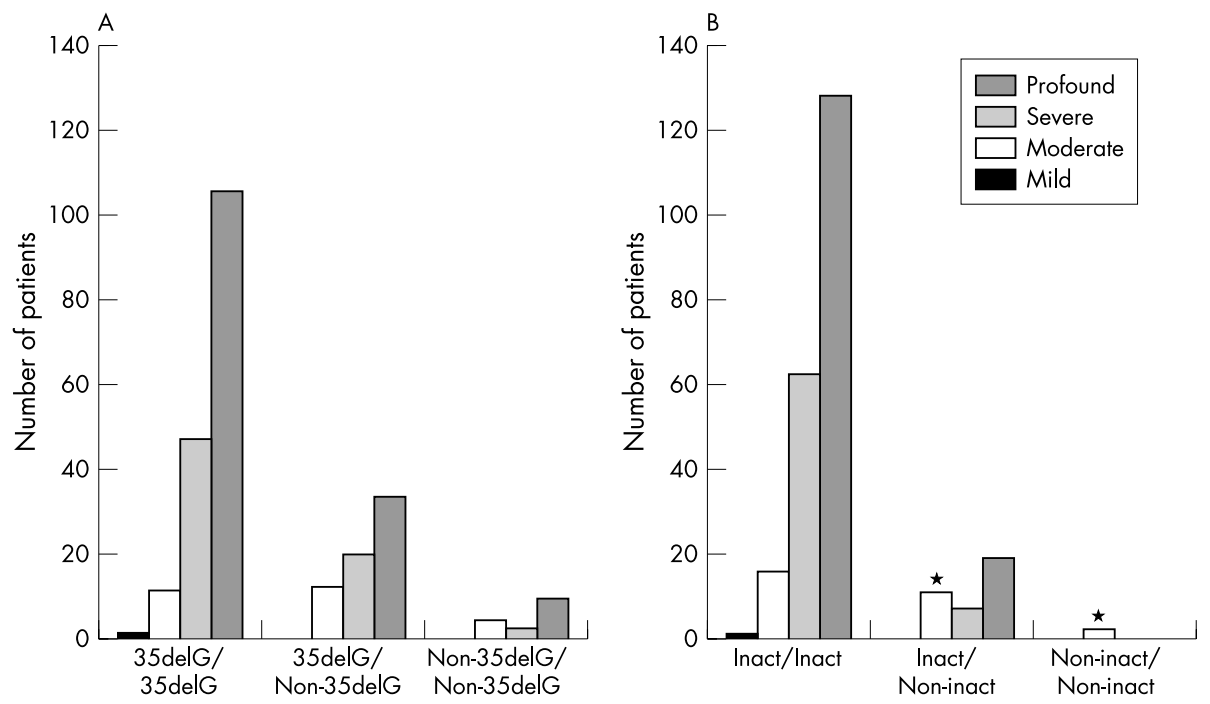

Figure 4 This shows the same as fig 1, but now with exclusion of specific genotypes that are associated with significantly less severe hearing impairment compared to the 35 delG homozygous genotype as indicated in fig 2 . The number of patients is indicated on the y axis. $\chi^{2}$ testing indicated that hearing impairment classes were non-randomly distributed across the different 35delG/non35delG and the inactivating/non-inactivating genotypes. For both genotype categories, a reduced contingency table was constructed, combining the mild and moderate category as well as the $35 \mathrm{delG} / \mathrm{non} 35 \mathrm{delG}$ and non-35delG/non-35delG genotypes or the inactivating/non-inactivating and the non-inactivating/non-inactivating categories. Asterisks indicate significantly high relative frequency according to the Fisher's exact probability test. 
Table 1 Overview of hearing impairment associated with specific GJB2 mutations as reported by previous studies. The upper panel represents mutations that are associated with significantly less severe hearing impairment with respect to 35delG homozygotes; the lower panel represents mutations that do not show significant differences with respect to 35delG homozygotes

\begin{tabular}{|c|c|c|c|}
\hline Genotype & This study & Previous studies & References \\
\hline $\begin{array}{l}\text { 35delG/V37I } \\
\text { 35delG/L90P } \\
\text { 35delG/delE12C } \\
35 \text { delG/ } \\
\text { IVS1+1G }>\text { A } \\
\text { V37I/V37I }\end{array}$ & $\begin{array}{l}\text { Mi (3) } \\
\text { Mi (4), Mo (5) } \\
\text { OMo, Se } \\
\text { Mo (6), Se } \\
\text { Mi, Mo }\end{array}$ & $\begin{array}{l}\text { Mi, Mo, Se (2), High frequency } \\
\text { Mi, Mo (15), High frequency (2), Se (2), Pr } \\
\text { Se (2), Se to } \operatorname{Pr} \\
\text { Mo (3), Se, } \operatorname{Pr}(3) \\
\text { Mi (2), Mo (4), Se, Se to } \operatorname{Pr}\end{array}$ & $\begin{array}{l}293233 \\
19293432 \quad 35-37 \\
283638 \\
34253235 \\
28-3132\end{array}$ \\
\hline $\begin{array}{l}\text { 35delG/W24X } \\
\text { 35delG/E47X } \\
\text { 35delG/167delT } \\
\text { 35delG/W77R } \\
\text { 35delG/V95M } \\
\text { 35delG/ } \\
\text { 313del14 } \\
\text { 35delG/R143W } \\
\text { 35delG/E147K } \\
\text { 35delG/R184P }\end{array}$ & $\begin{array}{l}\text { Se, } \operatorname{Pr} \\
\text { Se (6), } \operatorname{Pr}(4) \\
\text { ITMo (3), Se (5), } \operatorname{Pr}(3) \\
\text { Mo, Se, } \operatorname{Pr} \\
\text { Se (2) } \\
\text { Se, } \operatorname{Pr}(4) \\
\operatorname{Pr}(3) \\
\operatorname{Pr}(4) \\
\operatorname{Mo~(3),~Se,~Pr~(2)~}\end{array}$ & $\begin{array}{l}\text { Mo, Se (2), } \operatorname{Pr} \\
\text { Se, } \operatorname{Pr}(3) \\
\text { Mo (4), Se (3), } \operatorname{Pr}(8) \\
\text { Mo, } \operatorname{Pr}(13) \\
\text { / } \\
\text { Se to } \operatorname{Pr}(3), \operatorname{Pr}(6) \\
\operatorname{Pr} \\
/ \\
\text { Se to } \operatorname{Pr}(7), \operatorname{Pr}(2)\end{array}$ & $\begin{array}{l}3637 \\
313236 \\
293132363940 \\
313639 \\
634323839 \\
31 \\
2837\end{array}$ \\
\hline
\end{tabular}

The number of patients is indicated between brackets in cases where more than one patient with the respective phenotype has been reported.

Mi, mild; Mo, moderate; Se, severe; Pr, profound.

line with our findings. However, they included several affected individuals from certain families, which can lead to a potential bias, due to a shared genetic background. The main difference with the current study is that they only made a classification based on the number of 35delG alleles and were not able to identify specific GJB2 genotypes that are associated with a remarkably mild phenotype. Based on their results they concluded that the hearing loss due to GJB2 could not be predicted, even within families. In the study of Cohn et al, ${ }^{18} 167$ delT homozygotes were significantly more severely affected than 35delG homozygotes. Also, in this study multiple affected individuals from certain families were taken into account. In addition, they concluded that hearing impairment is very variable and suggested that other factors modify the phenotypic effects of GJB2 mutations. Considering previous publications on the GJB2 phenotype, some reports have given some evidence of a genotypephenotype correlation for GJB2, but these studies are limited compared to the current study.

In contrast to the above listed genotypes leading to mild hearing impairment, no significant differences could be detected between 35delG homozygotes and 35delG/ 313del14，35delG/R143W，35delG/E147K，35delG/W24X, 35delG/V95M, 35delG/W77R, 35delG/E47X, 35delG/167delT or $35 \mathrm{delG} / \mathrm{R} 184 \mathrm{P}$ compound heterozygous genotypes (fig 3). These findings have also been confirmed by other studies to some extent (table 1), and the combined data indicate that GJB2 related hearing impairment is mostly determined by the specific mutation combination. Variation in hearing impairment within each genotype category suggests that environmental factors or modifier genes, or both, are also involved but their contribution appears to be less important.

The finding that some GJB2 genotypes are associated with significantly less severe hearing impairment compared with 35delG homozygous mutations suggests that the significant differences between the different 35delG/non35delG and inactivating/non-inactivating categories (fig 1) are mainly due to the presence of milder genotypes in some subgroups. We confirmed this subgroup effect by repeating our comparisons with the exclusion of these mild mutation combinations. After exclusion, most but not all of the significant differences had disappeared (fig 4). Based on these results, we believe that it is very likely that the inactivating/non-inactivating and non-inactivating/non-inactivating categories still included remarkably mild mutations after the present exclusion. In table 2, we have listed all genotypes that were detected in single people with moderate hearing impairment and $\mathrm{PTA}_{0.5-4 \mathrm{kHz}}>57.5 \mathrm{~dB}$. These genotypes are not included in fig 2 because Fisher's exact probability testing only produced significant results between our group of 35delG homozygotes and single genotypes if the latter category was present in people with $\mathrm{PTA}_{0.5-}$ $4 \mathrm{kHz}<57.5 \mathrm{~dB}$. Nevertheless, these genotypes might eventually be labelled as significantly less severe compared to the 35delG/35delG genotype if a second person with the same

Table 2 List of mutation combinations in single patients showing moderate hearing impairment. Fisher's exact probability testing only produced significant results between our group of $35 \mathrm{delG}$ homozygotes and single genotypes if the latter category was present in people with PTA $\mathrm{O}_{0 .}$ $4 \mathrm{kHz}<57.5 \mathrm{~dB}$. The genotypes listed below might eventually be labelled as significantly less severe compared to the $35 \mathrm{delG} / 35 \mathrm{del} G$ genotype if a second person with the same genotype is found and if both people have PTA $_{0.5-4 \mathrm{kHz}} \leqslant 83 \mathrm{~dB}$

\begin{tabular}{|c|c|}
\hline GJB2 genotype & PTA $_{0.5-4 \mathrm{kHz}}$ \\
\hline $\begin{array}{l}\text { 35delG/V84L } \\
\text { 35delG/M93I } \\
\text { 35delG/S138N* } \\
\text { 35delG/R184W } \\
\text { 35delG/N206S } \\
\text { W24X/R184P } \\
\text { R32C/E47X } \\
\text { V84L/R184P } \\
\text { T123N/T123N* }\end{array}$ & $\begin{array}{l}63 \\
61 \\
70 \\
65 \\
65 \\
58 \\
59 \\
60 \\
60\end{array}$ \\
\hline
\end{tabular}

*The pathogenic nature of $\mathrm{S} 138 \mathrm{~N}$ and $\mathrm{T} 123 \mathrm{~N}$ is not proven. S138N was not described previously, and T123N was reported as a change with an unknown relation to disease. These variants were not found in 100 Belgian (S138N) or 400 American (T123N) control chromosomes respectively. The amino acids involved in both variants are not evolutionary conserved between Homo sapiens, Mus musculus, Cavia porcellus, and Ovis aries. 
Table 3 Functional properties of the more frequent GJB2 mutations as described in the literature. The effect on the degree of hearing impairment of these mutations in combination with a $35 \mathrm{del}$ G allele is also included

\begin{tabular}{llll}
\hline Mutation & Effect on hearing impairment (current study) & Functional properties & References \\
\hline 35delG & $\begin{array}{l}\text { Mild to profound, with most patients showing severe or profound } \\
\text { hearing impairment }\end{array}$ & No expression & 41 \\
IVS1+1G $>$ A & Significantly less severe compared with 35delG & No expression & 42 \\
V37I & Significantly less severe compared with 35delG & Complete loss of channel activity & 43 \\
W77R & No significant difference compared with 35delG & Complete loss of channel activity & $43-46$ \\
V84L & Possibly associated with less severe hearing impairment & Conductance similar to wild-type CX26 & 4347 \\
L90P & Significantly less severe compared with 35delG & Complete loss of channel activity & 4143 \\
V95M & No significant difference compared with 35delG & Conductance similar to wild-type CX26 & 47 \\
delE120 & Significantly less severe compared with 35delG & Complete loss of channel activity & 43 \\
R143W & No significant difference compared with 35delG & Conductance similar to wild-type CX26 & 47 \\
R184P & No significant difference compared with 35delG & Complete loss of channel activity & 4348 \\
\hline
\end{tabular}

genotype is found and if both people have $\mathrm{PTA}_{0.5-}$ $4 \mathrm{kHz} \leqslant 83 \mathrm{~dB}$. It is thus possible that the list of genotypephenotype correlations described in the present report can be easily extended to additional genotypes. Our study clearly demonstrates the feasibility of identifying specific mild GJB2 genotypes based on audiometric data from a relatively small number of patients. We would recommend establishing a large multicentre study to collect such data from as many people with GJB2-related deafness as is possible. Additional data may also make it feasible to predict the expected degree of hearing impairment more accurately.

For some of the more frequent GJB2 mutations, including 35delG, V37I, W77R, V84L, L90P, V95M, delE120, R143W, $\mathrm{R} 184 \mathrm{P}$, and IVSI+1G $>\mathrm{A}$, functional studies have been conducted. These studies analyse the expression and intercellular communication properties (including junctional conductance) of mutant CX26 protein in communication deficient cells (Xenopus oocytes, HeLa cells, or N2A cells). We attempted to relate results from these studies to our findings (table 3) but found this correlation difficult to make. For example, expression studies reveal that the 35delG and IVSI+1G $>$ A mutations do not yield any detectable CX26 protein and mRNA respectively. ${ }^{41}{ }^{42}$ Based on this result, a reasonable expectation would be that both mutations would have the same effect on hearing impairment. However, we observed 35delG/IVSI+lG $>$ A compound heterozygotes to have significantly $(\mathrm{p}<0.0001)$ less severe hearing impairment compared to $35 \mathrm{delG}$ homozygotes. As the conclusion that there is no mRNA for the IVS $1+1 G>A$ mutation is based on a DNA sequencing result, ${ }^{42}$ the presence of a very small amount of mRNA cannot be excluded, possibly providing an explanation for this discrepancy. Functional studies of the other mutants indicate that all are expressed with at most only a minor effect on translation. A complete loss of channel activity has been demonstrated for V37I, W77R, L90P, delE120, and R184P while V84L, V95M, and R143W mutant proteins induce a junctional conductance similar to wild-type CX26. There are numerous discrepancies between our data and these results (table 3), reflecting the limitations of in vitro systems when trying to mimic cellular conditions in the cochlea. Furthermore, these systems investigate junctional conductance and not changes in the pore structure that may influence permeability and gap junction properties.

Several studies have shown that CX26 forms homomeric and homotypic channels, but it may also interact with other inner ear connexins to form heteromeric and heterotypic channels. ${ }^{49}{ }^{50}$ The formation and function of heteromeric and heterotypic channels have not been investigated. It is also possible that interactions with other unidentified inner ear proteins exist. At a minimum, these discrepancies between functional data and our genotype-phenotype data indicate that it would be useful to analyse the validity of in vitro systems as a model for in vivo conditions.
In conclusion, our results demonstrate for the first time on a systematic basis that people cosegregating specific GJB2 genotypes have significantly less severe hearing impairment compared with 35delG homozygotes. The delineation of this genotype-phenotype correlation, together with data obtained by large multicentre follow up studies, may be valuable within the framework of universal newborn hearing screening. The purpose of this screening is the early detection and habilitation of children with congenital hearing loss. As GJB2 accounts for up to $50 \%$ of non-syndromic recessive hearing impairment, mutation analysis of this gene is routinely carried out in many newborns with hearing impairment in many countries. Children with congenital hearing loss are often referred at the age of 1-3 months for follow up screening and therapeutic intervention. ${ }^{51}$ Complementing physiological testing of hearing with the genotype-phenotype correlation we describe in this report may facilitate the selection of appropriate habilitation strategies for people with GJB2 related deafness. Furthermore, our study also demonstrates that GJB2 is clearly involved in mild and moderate hearing impairment, and we suggest that GJB2 mutation analysis is indicated in all patients with putative autosomal recessive non-syndromic hearing impairment, regardless of the severity of hearing impairment. In addition, the entire coding region as well as the splice site should be screened instead of only the recurrent mutations.

\section{Authors' affiliations}

K Cryns, R L Snoeckx, C M Van de Heyning, G Van Camp, Department of Medical Genetics, University of Antwerp, Antwerp, Belgium

E Orzan, Otosurgery Unit, University Hospital Padua, Padua, Italy A Murgia, E Leonardi, Department of Paediatrics, University of Padua, Padua, Italy

P L M Huygen, Department of Otorhinolaryngology, University Medical Centre St Radboud, Nijmegen, Netherlands

F Moreno, I del Castillo, Unidad de Genetica Molecular, Hospital Ramon y Cajal, Madrid, Spain

G Parker Chamberlin, H Azaiez, S Prasad, R A Cucci, R J H Smith, Molecular Otolaryngology Research Laboratories, Department of Otolaryngology, University of lowa, lowa City, USA

P J Govaerts, The Ear Group, Antwerp-Deurne, Belgium

P H Van de Heyning, Department of Otolaryngology, University of Antwerp, Antwerp, Belgium

This research was performed within the framework of the Interuniversity Attraction Poles program P5/19 of the Federal Office for Scientific, Technical, and Cultural Affairs, Belgium. This study was supported by grant G.0277.01 from the FWO (G Van Camp), NIH grant ROIDC02842 (R J H Smith), and grants from the European Community (QLG2-CT-1999-00988), CAICYT of Spanish Ministerio de Ciencia y Tecnología (SAF99-0025), and the Spanish Fondo de Investigaciones Sanitarias (FIS 00/0244) (F Moreno and I del Castillo).

*All authors contributed equally 


\section{REFERENCES}

1 Mehl AL, Thomson V. Newborn hearing screening: the great omission. Pediatrics 1998;101:E4

2 Mehl AL, Thomson V. The Colorado newborn hearing screening project, 1992-1999: on the threshold of effective population-based universal newborn hearing screening. Pediatrics 2002;109:E7.

3 Morton N. Genetic epidemiology of hearing impairment. Ann N Y Acad Sci 1991;630:16-31

4 Van Camp G, Smith RJH. Hereditary hearing loss homepage. www. via.ac.be/dnalab/hhh (accessed 28 November 2003).

5 Abe S, Usami S, Shinkawa H, Kelley PM, Kimberling WJ. Prevalent connexin 26 gene (GJB2) mutations in Japanese. J Med Genet 2000;37:41-3.

6 Denoyelle F, Weil D, Maw MA, Wilcox SA, Lench NJ, Allen-Powell DR, Osborn AH, Dahl HH, Middleton A, Houseman MJ, Dodé C, Marlin S, BoulilaElGaïed A, Grati M, Ayadi H, BenArab S, Bitoun P, Lina-Granade G, Godet J, Mustapha M, Loiselet J, El-Zir E, Aubois A, Joannard A, Levilliers J Garabédian ÉN, Mueller RF, McKinlay Gardner RJ, Petit C. Prelingual deafness: high prevalence of a 30 delG mutation in the connexin 26 gene. Hum Mol Genet 1997;6:2173-7.

7 Green GE, Scott DA, McDonald JM, Woodworth GG, Sheffield VC, Smith RJ. Carrier rates in the midwestern United States for GJB2 mutations causing inherited deafness. JAMA 1999;281:2211-6.

8 Liu XZ, Xia XJ, Ke XM, Ouyang XM, Du LL, Liu YH, Angeli S, Telischi FF, Nance WE, Balkany T, Xu LR. The prevalence of connexin 26 (GJB2) mutations in the Chinese population. Hum Genet 2002:111:394-7.

9 Zelante L, Gasparini P, Estivill X, Melchionda S, D'Agruma L, Govea N, Milá M, Della Monica M, Lutfi J, Shohat M, Mansfield E, Delgrosso K, Rappaport E, Surrey S, Fortina P. Connexin 26 mutations associated with the most common form of non-syndromic neurosensory autosomal recessive deafness (DFNB1) in Mediterraneans. Hum Mol Genet 1997:6:1605-9.

10 Denoyelle F, Lina-Granade G, Plauchu H, Bruzzone R, Chaîb H, LéviAcobas $F$, Weil D, Petit $C$. Connexin 26 gene linked to a dominant deafness. Nature 1998;393:319-20.

11 Morlé L, Bozon M, Alloisio N, Latour P, Vandenberghe A, Plauchu H, Collet L, Edery P, Godet J, Lina-Granade G. A novel C202F mutation in the connexin26 gene (GJB2) associated with autosomal dominant isolated hearing loss. J Med Genet 2000;37:368-70.

12 Kenneson A, Van Naarden Braun K, Boyle C. GJB2. (connexin 26) variants and nonsyndromic sensorineural hearing loss: a HuGE review, Genet Med 2002;4:258-74.

13 Calvo J, Rabionet R, Gasparini P, Estivill X. Connexins and deafness homepage. www.crg.es/deafness (accessed 28 November 2003).

14 Gasparini P, Rabionet R, Barbujani G, Melchionda S, Petersen M, Petersen M, Brondum-Nielsen K, Metspalu A, Oitmaa E, Pisano M, Fortina P, Zelante L, Estivill X, Genetic Analysis Consortium of GJB2 35delG. High carrier frequency of the 35 del $G$ deafness mutation in European populations. Eur J Hum Genet 2000;8:19-23.

15 Estivill X, Fortina P, Surrey S, Rabionet R, Melchionda S, D'Agruma L, Mansfield E, Rappaport E, Govea N, Milà M, Zelante L, Gasparini P. Connexin-26 mutations in sporadic and inherited sensorineural deafness. Lancet 1998;351:394-8.

16 Van Laer L, Coucke P, Mueller RF, Caethoven G, Flothmann K, Prasad SD Chamberlin GP, Houseman M, Taylor GR, Van de Heyning CM, Fransen E, Rowland J, Cucci RA, Smith RJ, Van Camp G. A common founder for the 35 delG GJB2 gene mutation in connexin 26 hearing impairment. J Med Genet 2001;38:515-8.

17 Murgia A, Orzan E, Polli R, Martella M, Vinanzi C, Leonardi E, Arslan E, Zacchello F. Cx26 deafness: mutation analysis and clinical variability. J Med Genet 1999;36:829-32.

18 Cohn ES, Kelley PM, Fowler TW, Gorga MP, Lefkowitz DM, Kuehn HJ, Schaefer GB, Gobar LS, Hahn FJ, Harris DJ, Kimberling WJ. Clinical studies of families with hearing loss attributable to mutations in the connexin 26 gene (GJB2/DFNB 1). Pediatrics 1999; 103:546-50.

19 Denoyelle F, Marlin S, Weil D, Moatti L, Chauvin P, Garabédian ÉN, Petit C. Clinical features of the prevalent form of childhood deafness, DFNB 1, due to a connexin-26 gene defect: implications for genetic counselling. Lancet 1999:353:1298-1303.

20 Orzan E, Polli R, Martella M, Vinanzi C, Leonardi M, Murgia A. Molecular genetics applied to clinical practice: the $\mathrm{C} \times 26$ hearing impairment. $\mathrm{Br} J$ Audiol 1999:33:291-5.

21 International Organization for Standardization. ISO 8253-1: Acoustics: audiometric test methods, I: basic pure tone air and bone conduction threshold audiometry. Geneva: International Organization for Standardization, 1989.

22 GENDEAF, European Thematic Network on Genetic Deafness, www.gendeaf.org (accessed 28 November 2003).

23 Scott DA, Kraft ML, Carmi R, Ramesh A, Elbedour K, Yairi Y, Srikumari Srisailapathy CR, Rosengren SS, Markham AF, Mueller RF, Lench NJ, Van Camp G, Smith RJ, Sheffield VC. Identification of mutations in the connexin 26 gene that cause autosomal recessive nonsyndromic hearing loss. Hum Mutat 1998:11:387-94.

24 Prasad S, Cucci RA, Green GE, Smith RJ. Genetic testing for hereditary hearing loss: connexin 26 (GJB2) allele variants and two novel deafness-causing mutations (R32C and 645-648delTAGA). Hum Mutat 2000;16:502-8.

25 ConSeq web server, http://conseq.bioinfo.tau.ac.il/ (accessed 28 November 2003).

26 Griffith AJ, Friedman TB. Auditory function and the M34T allele of connexin 26. Arch Otolaryngol Head Neck Surg 2002;128:94

27 Kelley PM, Harris DJ, Comer BC, Askew JW, Fowler T, Smith SD, Kimberling WJ. Novel mutations in the connexin 26 gene (GJB2) that cause autosomal recessive (DFNB1) hearing loss. Am J Hum Genet 1998;62:792-9.
28 Rabionet R, Zelante L, López-Bigas N, D'Agruma L, Melchionda S, Restagno G, Arbonés ML, Gasparini P, Estivill X. Molecular basis of childhood deafness resulting from mutations in the GJB2 (connexin 26) gene. Hum Genet 2000;106:40-4.

29 Wilcox SA, Saunders K, Osborn AH, Arnold A, Wunderlich J, Kelly T, Collins V, Wilcox U, McKinlay Gardner R, Kamarinos M, Cone-Wesson B, Williamson R, Dahl HH. High frequency hearing loss correlated with mutations in the GJB2 gene. Hum Genet 2000;106:399-405.

30 Bason L, Dudley T, Lewis K, Shah U, Potsic W, Ferraris A, Fortina P, RappaportE, Krantz ID. Homozygosity for the V37I Connexin 26 mutation in three unrelated children with sensorineural hearing loss. Clin Genet 2002;61:459-64.

31 Kenna MA, Wu BL, Cotanche DA, Korf BR, Rehm HL. Connexin 26 studies in patients with sensorineural hearing loss. Arch Otolaryngol Head Neck Surg 2001; 127:1037-42.

32 Marlin S, Garabédian ÉN, Roger G, Moatti L, Matha N, Lewin P, Petit C, Denoyelle $\mathrm{F}$. Connexin 26 gene mutations in congenitally deaf children: piffalls for genetic counseling. Arch Otolaryngol Head Neck Surg 2001; 127:927-33.

33 Engel-Yeger B, Zaaroura S, Zlotogora J, Shalev S, Hujeirat $Y$ Carrasquillo MM, Saleh B, Pratt H. Otoacoustic emissions and brainstem evoked potentials in compound carriers of connexin 26 mutations. Hear Res 2003;175:140-51

34 Janecke AR, Hirst-Stadlmann A, Günther B, Utermann B, Müller T, Löffler J, Utermann G, Nekahm-Heis D. Progressive hearing loss, and recurrent sudden sensorineural hearing loss associated with GJB2 mutations-phenotypic spectrum and frequencies of GJB2 mutations in Austria. Hum Genet 2002;111:145-53.

35 Löffler J, Nekahm D, Hirst-Stadlmann A, Günther B, Menzel HJ, Utermann G, Janecke AR. Sensorineural hearing loss and the incidence of $C \times 26$ mutations in Austria. Eur J Hum Genet $2001 ; 9: 226-30$

36 Zoll B, Petersen L, Lange K, Gabriel P, Kiese-Himmel C, Rausch P, Berger J, Pasche B, Meins M, Gross M, Berger R, Kruse E, Kunz J, Sperling K, Lacocone $F$. Evaluation of Cx26/GJB2 in German hearing impaired persons: mutation spectrum and detection of disequilibrium between M34T (c. 101T $>C$ ) and -493del10. Hum Mutat 2003;20:98.

37 Pampanos A, Economides J, lliadou V, Neou P, Leotsakos P, Voyiatzis N, Eleftheriades N, Tsakanikos M, Antoniadi T, Hatzaki A, Konstantopoulou I, Yannoukakos D, Gronskov K, Brondum-Nielsen K, Grigoriadou M, Gyftodimou J, Iliades T, Skevas A, Petersen MB. Prevalence of GJB2 mutations in prelingual deafness in the Greek population. Int J Pediatr Otorhinolaryngol 2002;65:101-8.

38 Gabriel H, Kupsch P, Sudendey J, Winterhager E, Jahnke K, Lautermann J. Mutations in the connexin26/GJB2 gene are the most common event in nonsyndromic hearing loss among the German population. Hum Mutat 2001; 17:521-2.

39 Mueller RF, Nehammer A, Middleton A, Houseman M, Taylor GR, BitnerGlindzciz M, Van Camp G, Parker M, Young ID, Davis A, Newton VE, Lench NJ. Congenital non-syndromal sensorineural hearing impairment due to connexin 26 gene mutations-molecular and audiological findings. Int J Pediatr Otorhinolaryngol 1999;50:3-13

40 Sobe T, Vreugde S, Shahin H, Berlin M, Davis N, Kanaan M, Yaron Y, OrrUrtreger A, Frydman $M$, Shohat $M$, Avraham KB. The prevalence and expression of inherited connexin 26 mutations associated with nonsyndromic hearing loss in the Israeli population. Hum Genet 2000;106:50-7.

41 D'Andrea P, Veronesi V, Bicego M, Melchionda S, Zelante L, Di lorio E, Bruzzone R, Gasparini P. Hearing loss: frequency and functional studies of the most common connexin26 alleles. Biochem Biophys Res Commun 2002;296:685-91.

42 Shahin H, Walsh T, Sobe T, Lynch E, King MC, Avraham KB, Kanaan M. Genetics of congenital deafness in the Palestinian population: multiple connexin 26 alleles with shared origins in the Middle East. Hum Genet 2002:110:284-9.

43 Bruzzone R, Veronesi V, Gomès D, Bicego M, Duval N, Marlin S, Petit C, D'Andrea P, White TW. Loss-of-function and residual channel activity of connexin 26 mutations associated with non-syndromic deafness. FEBS Lett 2003;533:79-88.

44 Richard G, White TW, Smith LE, Bailey RA, Compton JG, Paul DL, Bale SJ. Functional defects of $C \times 26$ resulting from a heterozygous missense mutation in a family with dominant deaf-mutism and palmoplantar keratoderma. Hum Genet 1998; 103:393-9.

45 Martin PE, Coleman SL, Casalotti SO, Forge A, Evans WH. Properties of connexin26 gap junctional proteins derived from mutations associated with non-syndromal heriditary deafness. Hum Mol Genet 1999;8:2369-76.

46 White TW, Deans MR, Kelsell DP, Paul DL. Connexin mutations in deafness. Nature 1998;394:630-1.

47 Wang $\mathrm{H}-\mathrm{L}$, Chang W-T, Li AH, Yeh T-H, Wu C-Y, Chen M-S, Huang P-C. Functional analysis of connexin-26 mutants associated with hereditary recessive deafness. J Neurochem 2003;84:735-742.

48 Thönnissen $E$, Rabionet R, Arbonès ML, Estivill X, Willecke K, OH T. Human connexin26 (GJB2) deafness mutations affect the function of gap junction channels at different levels of protein expression. Hum Genet 2002;111:190-7.

49 Stauffer KA. The gap junction proteins beta 1-connexin (connexin-32) and beta 2-connexin (connexin-26) can form heteromeric hemichannels. J Biol Chem 1995;270:6768-72.

50 Lee MJ, Rhee SK. Heteromeric gap junction channels in rat hepatocytes in which the expression of connexin26 is induced. Mol Cells 1998;8:295-300.

51 Govaerts PJ, Yperman M, De Ceulaer G, Daemers K, Van Driessche K, Somers T, Offeciers FE. A two-stage bipodal screening model for universal neonatal hearing screening. Otol Neurotol $2001 ; 22: 850-4$. 